\title{
Positioner Secondary Angle
}

National Cancer Institute

\section{Source}

National Cancer Institute. Positioner Secondary Angle. NCI Thesaurus. Code C69223.

Position of an object in reference to a patient, from the caudal to cranial direction. 